\title{
, SERUM PROTEIN FRACTIONS: A COMPARISON OF PRECIPITATION METHODS WITH ELECTROPHORESIS
}

\author{
BY \\ B. LEVIN, V. G. OBERHOLZER, AND T. P. WHITEHEAD \\ From the Department of Pathology, Queen Elizabeth Hospital for Children, Hackney, \\ and the Mothers' Hospital, London
}

(RECEIVED FOR PUBLICATION MARCH 17, 1950)

The proteins of human serum and their changes in disease have been extensively studied by salt fractionation methods, and more recently by electrophoresis. Although there are limitations to electrophoresis (Petermann, Young, and Hogness, 1947), it has the great advantage that the albumin and globulin fractions obtained are homogeneous, although this is based upon the single property of mobility in an electric field. Unfortunately the method is not practicable for routine serum protein analysis, and a simple procedure for the chemical determination of albumin and $a-, \beta-$, and $\gamma$-globulins in serum proteins, giving results reasonably consistent with those obtained by electrophoretic analysis, would facilitate study of the alterations which occur in disease.

The so-called albumin fraction obtained after precipitation of globulin with $22.5 \%$ sodium sulphate is almost always larger than the albumin as determined by electrophoresis (Taylor and Keys, 1943 ; Dole and Braun, 1944). Petermann et al. (1947), reviewing the results reported in the literature obtained by both methods and also their own results, concluded that the Howe albumin fraction included $\alpha$-globulin as well as albumin. This was more valid for sera from normal persons. Cohn and Wolfson (1947) arrived at the same conclusion.

Pillemer and Hutchinson (1945) reported that values for albumin in close accord with those found by electrophoresis were obtained by precipitating the globulin with aqueous methyl alcohol at $p \mathrm{H} 6.7-6.9$, and ionic strength 0.03 , providing the temperature was kept at $0^{\circ} \mathrm{C}$. These results were confirmed by Martin and Morris (1949), who showed that the two methods gave values within $5 \%$ of each other. Majoor (1947), on the basis of solubility curves, found that the filtrate after precipitation with $26.8 \%$ sodium sulphate also gave values for albumin in close agreement with electrophoresis, and this was supported by the work of Milne (1947) using the same concentration of sodium sulphate. Wolfson, Cohn, Calvary, and Ichiba (1948) used $28.0 \%$ sodium sulphite for the estimation of albumin and reported good agreement.

Several precipitation methods have been advocated recently for the estimation of $\gamma$-globulin. Kibrick and Blonstein (1948) used $15.75 \%$ sodium sulphate and found agreement with electrophoresis mostly within $0.1 \mathrm{~g}$., but an occasional result showed a greater difference. Jager and Nickerson (1948) precipitated the globulin 
by $33 \%$ saturation with ammonium sulphate using a saturated solution brought to $p \mathrm{H} 7$ by dilute ammonium hydroxide, obtaining good agreement with electrophoresis. Similar results were also obtained by Wolfson et al. (1948) using $1.89 \mathrm{M}$ ammonium sulphate in $4 \%$ sodium chloride solution for precipitation of $\gamma$-globulin.

The present investigation was initiated to find a reasonably simple micro-analysis of serum protein fractions by precipitation methods, giving results which would be consistent with electrophoretic analysis.

\section{Experimental}

Material.-An adult pooled human serum was obtained by mixing 1-ml. amounts of serum from 72 donors of whom 38 were Group 0,27 were Group A, six were Group B, and one was group AB. Three of the other sera were pooled infants' sera, and the remainder were from patients with a variety of conditions.

Methods.-For determining the total nitrogen in $0.1 \mathrm{ml}$. serum the micro-Kjeldahl method was used. Non-protein nitrogen was determined after precipitation of protein with $10 \%$ trichloracetic acid. In all fractions nitrogen figures were converted to protein by the factor 6.25. (All concentrations of precipitating reagents are given as initial concentrations except where otherwise stated.) The $22.5 \%$ sodium sulphate, $27.2 \%$ sodium sulphate, and $28.0 \%$ sodium sulphite solutions are made up at $37^{\circ} \mathrm{C}$. and kept at this temperature until required. All precipitations and other manipulations with these reagents until the removal of the aliquot for analysis, are carried out at a temperature close to $37^{\circ} \mathrm{C}$., using a warm water-bath if necessary. By this means, we have found no difficulty in using such high concentrations or reagents.

The use of ether instead of filtration, as in Kingsley's modification (1940) of the Howe method, in precipitations using sodium sulphate or sodium sulphite solutions was found to be very convenient. It is necessary to avoid vigorous shaking in the presence of ether, especially when using $27.2 \%$ sodium sulphate and $28.0 \%$ sodium sulphite, as these precipitations were found to be very sensitive in this respect. Thus we have found that if shaking is merely prolonged for 30 seconds, the precipitate of protein is increased by approximately $15 \%$. Slight variations in other factors, e.g., temperature, grades of ether, time of centrifuging, were shown to have no effect on the precipitation.

Estimation of " Albumin plus $\alpha$-Globulin " with 22.5\% Sodium Sulphate.-Kingsley's modification (1940) of the Howe method was used. To $2.9 \mathrm{ml}$. of $22.5 \%$ sodium sulphate is added $0.1 \mathrm{ml}$. serum, a $2 \mathrm{ml}$. aliquot being removed for estimation by the micro-Kjeldahl method.

Estimation of Albumin with 27.2\% Sodium Sulphate (Kibrick and Blonstein, 1948). - Serum, $0.1 \mathrm{ml}$., is added to $2.0 \mathrm{ml}$. of $27.2 \%$ sodium sulphate. The tube is stoppered and inverted slowly several times and then allowed to stand for one hour at $37^{\circ} \mathrm{C}$. About $1 \mathrm{ml}$. ether is added, the mixture shaken gently for about 10 seconds, and then centrifuged for about three to four minutes using centrifuge cups containing warm water to avoid crystallization. Then $1.5 \mathrm{ml}$. of the lower clear aqueous layer is taken for micro-Kjeldahl determination.

Estimation of Albumin with $\mathbf{2 8 . 0} \%$ Sodium Sulphite (Wolfson et al., 1948). - Serum, $0.1 \mathrm{ml}$., is added to $2.4 \mathrm{ml} .28 .0 \%$ sodium sulphite and the two mixed by inverting slowly several times. Ether, $1 \mathrm{ml}$, is added, and keeping the tube horizontal it is shaken very gently about six times and then centrifuged for three to four minutes at 3,000 r.p.m. Then $1.5 \mathrm{ml}$. of the clear lower layer is transferred for micro-Kjeldahl estimation. 


\begin{tabular}{|c|c|c|c|c|c|c|c|c|c|}
\hline \multirow{2}{*}{ No. } & \multirow{2}{*}{ Subjects } & \multirow{2}{*}{$\begin{array}{c}\text { Total } \\
\text { Protein }\end{array}$} & \multicolumn{4}{|c|}{ Albumin } & \multicolumn{2}{|c|}{$\begin{array}{c}\text { Albumin } \\
\text { Plus } \alpha \text {-Globulin }\end{array}$} & \multirow{2}{*}{ 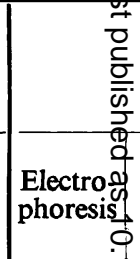 } \\
\hline & & & $\begin{array}{l}\text { Electro- } \\
\text { phoresis }\end{array}$ & $\begin{array}{c}26 \% \text { oł } \\
\text { Sodium } \\
\text { Sulphate }\end{array}$ & $\begin{array}{l}27 \% \\
\text { Sodium } \\
\text { Sulphite }\end{array}$ & $\begin{array}{l}\text { Methyl } \\
\text { Alcohol }\end{array}$ & $\begin{array}{l}\text { Electro- } \\
\text { phoresis }\end{array}$ & $\begin{array}{c}21.8 \% \\
\text { Sodium } \\
\text { Sulphate }\end{array}$ & \\
\hline $\begin{array}{r}1 \\
2 \\
3 \\
4 \\
5 \\
6 \\
7 \\
8 \\
9 \\
10\end{array}$ & 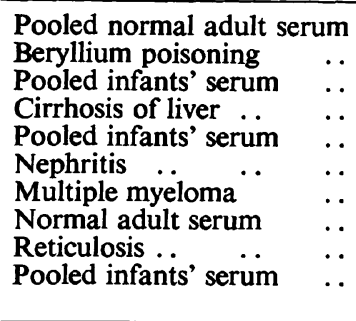 & $\begin{array}{r}7.29 \\
8.54 \\
6.52 \\
11.47 \\
6.11 \\
7.54 \\
11.13 \\
7.02 \\
5.99 \\
6.01\end{array}$ & $\begin{array}{l}3.77 \\
3.78 \\
3.71 \\
2.16 \\
3.25 \\
3.23 \\
2.80 \\
3.18 \\
2.43 \\
3.86\end{array}$ & $\begin{array}{l}3.82 \\
3.55 \\
3.68 \\
1.50 \\
3.42 \\
3.24 \\
2.29 \\
3.38 \\
2.80 \\
3.57\end{array}$ & $\begin{array}{l}3.66 \\
3.09 \\
3.35 \\
1.83 \\
3.47 \\
2.81 \\
1.70 \\
2.55 \\
\overline{3.67}\end{array}$ & $\begin{array}{l}3.86 \\
\overline{3.28} \\
0.92 \\
3.29 \\
2.57 \\
0.95 \\
3.38 \\
\overline{4.27}\end{array}$ & $\begin{array}{l}5.16 \\
4.95 \\
4.47 \\
3.23 \\
4.09 \\
4.24 \\
4.06 \\
4.83 \\
3.80 \\
4.80\end{array}$ & $\begin{array}{l}4.76 \\
4.84 \\
4.33 \\
2.68 \\
4.07 \\
4.55 \\
3.67 \\
4.33 \\
3.56 \\
4.17\end{array}$ & $\begin{array}{l}1.39 \text { cक } \\
1.17 \text { oे } \\
0.76 \text { वे } \\
1.07 \\
0.84 \\
1.01 \\
1.26 \text { के } \\
1.65 \text { के } \\
1.37 \text { ㅇ } \\
0.94\end{array}$ \\
\hline
\end{tabular}

* Albumin as determined by methyl alcohol was actually slightly higher than the albumin and $a$-globulin determined by precipitation 0 $\ddagger$ All concentrations of reagents are the fifl

Estimation of Albumin using Methyl Alcohol (Pillemer and Hutchinson, 1945).The method of Pillemer and Hutchinson was modified to avoid the use of a refrigerated centrifuge. All reagents and pipettes are chilled to $0^{\circ} \mathrm{C}$. before use. Serum, $0.2 \mathrm{ml}$, is placed in a $10 \mathrm{ml}$. centrifuge tube which is then kept in melting ice for 15 minutes; $0.1 \mathrm{ml}$. acetic acid-sodium acetate buffer solution, followed by $0.7 \mathrm{ml}$. of the aqueous methyl alcohol, both at $0^{\circ} \mathrm{C}$., are added, the tube being removed after each addition in order to mix the contents. The whole is then left in ice water for a further 30 minutes. The mixture is centrifuged until the supernatant is clear, the tubes being placed in $50-\mathrm{ml}$. centrifuge cups containing crushed ice. It was also found necessary to transfer the centrifuge tubes at the end of four minutes to fresh cups packed with crushed ice to ensure a constant temperature of $0^{\circ} \mathrm{C}$. Then $0.5 \mathrm{ml}$. of the clear supernatant is removed for micro-Kjeldahl estimation.

Estimation of $\gamma$-Globulin with $15.75 \%$ Sodium Sulphate (Kibrick and Blonstein, 1948).- Serum, $0.1 \mathrm{ml}$., is added to $2.0 \mathrm{ml}$. of $15.75 \%$ sodium sulphate, mixed, and allowed to stand at $37^{\circ} \mathrm{C}$. for one hour. Then $1 \mathrm{ml}$. ether is added, and the whole shaken gently. After centrifuging for three to four minutes, $1.5 \mathrm{ml}$. of the clear supernatant is transferred for nitrogen estimation by the micro-Kjeldahl method. The difference between this and the total nitrogen represents $\gamma$-globulin.

Estimation of $\gamma$-Globulin with Saturated Ammonium Sulphate Solution at pH 7.0 (Jager and Nickerson, 1948). - The method of precipitation given by these authors was followed, but the globulin was finally determined by the micro-Kjeldahl method after removal of ammonia by aeration. Precipitation is effected in a 30-ml. conical centrifuge tube drawn from glass tubing of $20 \mathrm{~mm}$. bore. Serum, $0.2 \mathrm{ml}$., is used to which $0.1 \mathrm{ml}$. saturated ammonium sulphate solution is added drop by drop. A horizontal burette made from capillary tubing drawn out to a very fine jet was used to deliver the ammonium sulphate solution in at least 10 drops with mixing after each drop. This was facilitated by a thin film of vaseline applied to the outer surface of the jet. After standing overnight at $4^{\circ} \mathrm{C}$., the tube is centrifuged for 30 minutes at $1,500-2,000$ r.p.m. The supernatant is removed as completely as possible with a 
ANALYSIS §

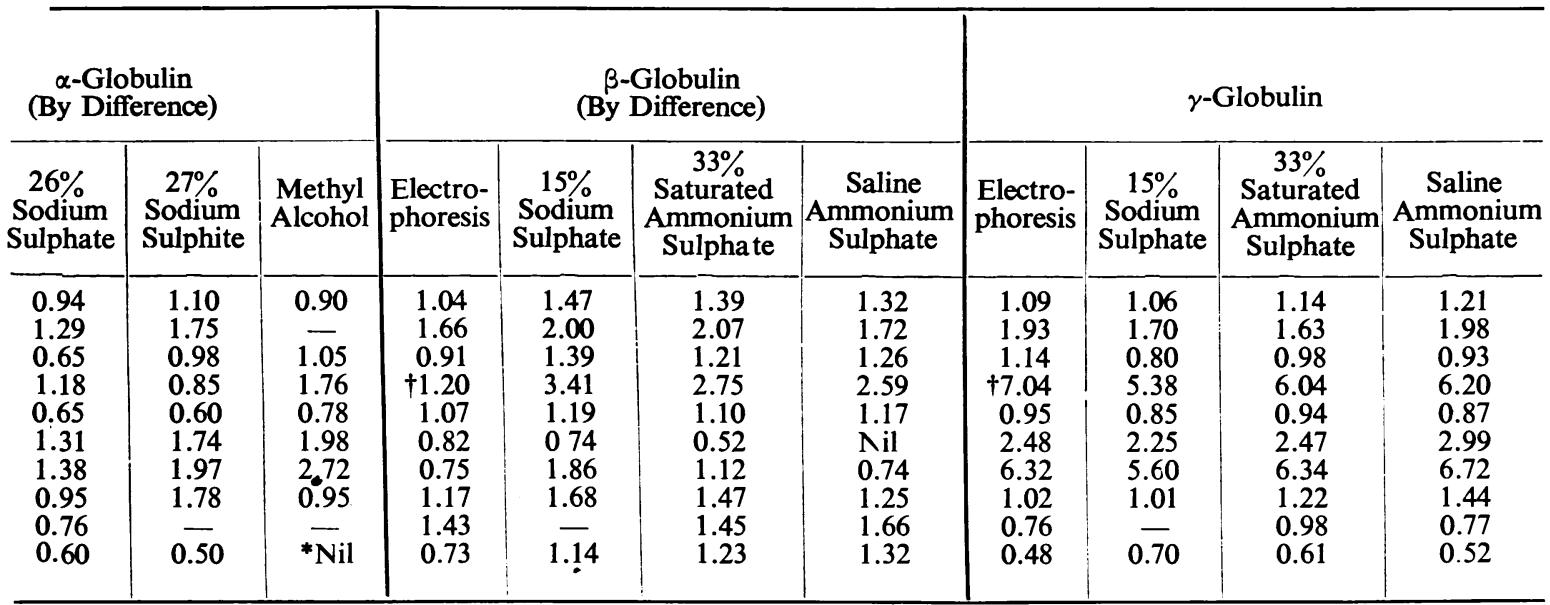

$21.8 \%$ sodium sulphate. † These results are appıoximations as $\beta$-globulin could not be accurately separated from $\gamma$-globulin by electrophoresis. concentrations. $\$$ All calculations given in $\mathrm{g} .100 \mathrm{ml}$.

capillary pipette without disturbing the precipitate, and the latter washed by suspension with $0.6 \mathrm{ml} .33 \%$ saturated ammonium sulphate solution using a fine glass rod to effect mixing. After centrifuging for 30 minutes the supernatant is removed as before.

For the removal of ammonia, $2 \mathrm{ml}$. $2 \mathrm{~N}$ sodium hydroxide solution is added to the precipitate and five or six drops of octyl alcohol to prevent frothing. Air freed from ammonia is now drawn through the solution in the centrifuge tube into another tube containing $1 \%$ boric acid solution and a few drops of Tashiro's indicator. A moderate current of air removes the ammonia completely in approximately 30 minutes, this being shown by the absence of colour change over a period of 10 minutes after renewal of the boric acid solution. The final solution is then transferred to a $50-\mathrm{ml}$. Kjeldahl flask for nitrogen estimation in the usual way. That there is no loss of nitrogen from the protein in this method has been shown by the analysis of known amounts of protein after the ammonia of added ammonium sulphate solution has been removed by aeration.

Estimation of $\gamma$-Globulin using Saline Ammonium Sulphate Solution (Wolfson et al., 1948). - The method of precipitation given was essentially followed, but here again the globulin was determined by micro-Kjeldahl analysis after removal of ammona. In order to avoid transfer, the globulin is precipitated in a $30-\mathrm{ml}$. centrifuge tube by the addition of $0.2 \mathrm{ml}$. serum to $4.8 \mathrm{ml}$. of the saline ammonium sulphate solution and mixed by slow inversion for one to two minutes. After centrifuging for 30 minutes at 3,000 r.p.m. the clear supernatant is removed by decantation from the closely packed precipitate, the tube inverted and allowed to drain for 10 minutes. The precipitate is dissolved in $2 \mathrm{ml}$. $2 \mathrm{~N}$ sodium hydroxide solution, care being taken to wash the sides of the tube, and then five to six drops of octyl alcohol are introduced. Ammonia is removed by aeration and the nitrogen estimated by micro-Kjeldahl analysis as before.

\section{Results}

The results of the analysis of 10 different sera are shown in the table, in which concentrations stated are the final, and not the initial, concentrations of reagents. 
Duplicate analyses were always performed and the means taken ; in all methods there was no difficulty in getting good duplicate results. As indicated below, $a$ globulin was calculated by the difference between the fraction obtained by precipitation with $22.5 \%$ sodium sulphate and the albumin as determined by $27.2 \%$ sodium sulphate, $28.0 \%$ sodium sulphite, and methyl alcohol precipitation respectively. $\beta$ - and $\gamma$-Globulin together was calculated by the difference between the total protein and the fraction obtained by $22.5 \%$ sodium sulphate. The difference between this and the experimentally determined $\gamma$-globulin gave $\beta$-globulin. Electrophoresis (by Dr. H. Hoch) was carried out using a veronal buffer at $p \mathrm{H} 8.6$ and ionic strength 0.15 , except for serum 4 when phosphate buffer $p H 7.4$ and ionic strength 0.1 was used.

\section{Discussion}

In general it may be stated that the albumin and globulin fractions obtained by precipitation methods and by electrophoresis could not be expected to give identical results ; if these were obtained, it could only be fortuitous, due to the inclusion of a certain amount of another fraction being estimated.

Albumin and $a$-Globulin.-The results using $22.5 \%$ sodium sulphate support the conclusion of Petermann et al. (1947) that this albumin fraction includes a-globulin as well as albumin. The agreement between this fraction and the albumin and a-globulin found by electrophoresis is reasonably good, the difference in most cases being not more than $0.4 \mathrm{~g}$. \%.

Albumin.-Of the three methods, $27.2 \%$ sodium sulphate gave the most satisfactory results for all sera, the mean deviation from the electrophoresis results being $9 \%$ compared with $15 \%$ and $22 \%$ for $28.0 \%$ sodium sulphite and methyl alcohol respectively. For normal sera agreement between precipitation methods and electrophoresis is much closer, the mean deviation being $6 \%, 9 \%$, and $6 \%$ for $27.2 \%$ sodium sulphate, $28.0 \%$ sodium sulphite, and methyl alcohol respectively. The results we have obtained with pathological sera using methyl alcohol have not been so good as those reported by other investigators, in every case very low values being obtained. It was found in the latter part of the investigation that the sodium sulphite solution deteriorates, and should be made up freshly each week. Some of the low results shown in the table may possibly be due to this, since old solutions were found to give low results.

$\gamma$-Globulin. - A comparison of the three methods used with electrophoresis shows that all give reasonably good agreement for both normal and pathological sera, the mean deviation being $16 \%$ for $15.75 \%$ sodium sulphate and $12 \%$ for both the ammonium sulphate methods. As might be expected, the sodium sulphate method agrees less well with electrophoresis than the ammonium sulphate methods, since in the former the $\gamma$-globulin is estimated by difference. Thus, a small experimental error in the determination of nitrogen in the supernatant after precipitation of the globulin will be magnified into much greater errors in the $\gamma$-globulin. Even though there is little to choose between the other two methods, $33 \%$ saturation with ammonium sulphate gives a slightly better spread of deviation from the electrophoresis results. However, this method is technically more difficult and requires overnight precipitation. The difference between the two methods is not sufficiently significant to make a choice. 
The experimental results indicate that for the determination of true albumin the best method is $27.2 \%$ sodium sulphate, and for $\gamma$-globulin either saline or saturated ammonium sulphate. If, as our results and those of previous investigators show, the albumin fraction determined by $22.5 \%$ sodium sulphate may be taken as albumin plus $a$-globulin, the value of $\alpha$ - and $\beta$-globulin may be determined by difference. This investigation shows that it is quite feasible to estimate all the fractions by precipitation methods in $0.5 \mathrm{ml}$. serum with results which agree sufficiently closely with electrophoresis to enable chemical methods to be used for the study of alterations in the pattern of serum proteins occurring in disease, or to follow quantitatively the changes which take place during progress or treatment.

\section{Summary}

Several precipitation methods for the estimation of true albumin and of $\gamma$-globulin have been modified for small amounts of serum and the final analysis made by the micro-Kjeldahl method, and the results obtained compared with electrophoresis. The selected methods for a number of normal and pathological sera gave results in good agreement with those obtained by electrophoresis. It is thus possible to carry out an analysis of serum proteins for albumin and $\alpha-, \beta$-, and $\gamma$-globulins by chemical precipitation methods using only $0.5 \mathrm{ml}$. serum.

We wish to thank Dr. H. Hoch for carrying out the electrophoretic analyses on the sera. The above forms part of a larger investigation on serum protein levels of infants undertaken by B. Levin, Helen M. Mackay (member of the scientific staff of the Medical Research Council), and Catherine A. Neill, with the assistance of V. G. Oberholzer and T. P. Whitehead, who gratefully acknowledge grants from the Medical Research Council.

\section{REFERENCES}

Cohn, C., and Wolfson, W. Q. (1947). J. Lab. clin. Med., 32, 1203.

Dole, V. P., and Braun, E. (1944). J. clin. Invest., 23, 708.

Jager, B. V., and Nickerson, M. (1948). J. biol. Chem., 173, 683.

Kibrick, A. C., and Blonstein, M. (1948). Ibid., 176, 983.

Kingsley, G. R. (1940). Ibid., 133, 731.

Majoor, C. L. H. (1947). Ibid., 169, 583.

Martin, N. H., and Morris, R. (1949). J. clin. Path., 2, 64.

Milne, J. (1947). J. biol. Chem., 169, 595.

Petermann, M. L., Young, N. F., and Hogness, K. R. (1947). Ibid., 169, 379.

Pillemer, L., and Hutchinson, M. C. (1945). Ibid., 158, 299.

Taylor, H. L., and Keys, A. (1943). Ibid., 148, 379.

Wolfson, W. Q., Cohn, C., Calvary, E., and Ichiba, F. (1948). Amer. J. clin. Path., 18, 723. 